\title{
Efficacy of biorhythmic transdermal combined hormone treatment in relieving climacteric symptoms: a pilot study
}

This article was published in the following Dove Press journal:

International Journal of General Medicine

25 February 201I

Number of times this article has been viewed

\section{B Formby \\ F Schmidt}

The Rasmus Institute for Medical Research, Program in Reproductive Endocrinology, Santa Barbara, CA, USA
Correspondance: B Formby

The Rasmus Institute for Medical

Research, 1625 Overlook Lane,

Santa Barbara, CA 93103, USA

Tel + I 805965 I724

Email rasmusinstitute@aol.com
Objective: To evaluate the efficacy of a combination of bioidentical combined $17 \beta$-estradiol and progesterone transdermal delivery system (lipophilic emulsion-type base) to relieve climacteric symptoms. The hormonal replacement was given during a period of 6 months at four different cyclic doses to mimic the normal ovary secretory pattern.

Design: An open, randomized, comparative, between-patient trial conducted over 6 months in 29 menopausal women with climacteric symptoms assessed with the Kupperman index at baseline and during treatments. Saliva and serum values of $17 \beta$-estradiol and progesterone were quantitated before treatment and after 3 and 6 months. Pharmacokinetic data following transdermal administration of $17 \beta$-estradiol $(0.3 \mathrm{mg}$, daily) and progesterone (100 mg, daily) were calculated from saliva levels using high-performance liquid chromatography analysis.

Results: Improvement in climacteric symptoms was reported in $93 \%$ of women evaluated before and after 3 and 6 months of treatment. Values of saliva $17 \beta$-estradiol increased after 6 months from $0.6 \pm 0.3 \mathrm{pg} / \mathrm{mL}$ to $14.1 \pm 3.3 \mathrm{pg} / \mathrm{mL}$, and the values of serum $17 \beta$-estradiol increased from $3.3 \pm 2.8 \mathrm{pg} / \mathrm{mL}$ to $80.6 \pm 21.9 \mathrm{pg} / \mathrm{mL}$. Of responders, $88 \%$ characterized symptom relief as complete. No adverse health-related events were attributed to the bioidentical hormone therapy. Time to maximum saliva concentrations ( $T \max$ ), in all experimental cases, was observed after 6 hours. Baseline values were reached within 24 hours, indicating a diurnal rhythm of $17 \beta$-estradiol seen in normally cyclic women over the 24 -hour period, ie, its daily biological rhythm.

Conclusion: Percutaneous absorption of $17 \beta$-estradiol, as well as the absorption of progesterone, was associated with relief of climacteric symptoms. The cyclical transdermal delivery of combined bioidentical hormones may be advantageous because it mimics the secretory profiles of $17 \beta$-estradiol and progesterone in normally cyclic women over a 28 -day period. Larger studies are needed to determine the long-term effects of our therapy.

Keywords: menopause, transdermal, 17ß-estradiol, circadian rhythms, estrogen homeostasis

\section{Introduction}

Ovarian hormone production in women peaks at the age of 25 years. After that, the decline is about $1 \%-3 \%$ annually. By the time a woman reaches 40 years, hormone production has fallen off $15 \%-45 \%$. Although the average age of menopause (the final monthly cycle) is 51 years, it takes decades of declining hormone production to get there. Only a very small amount of $17 \beta$-estradiol is still produced from adrenal precursors. More than $70 \%$ of all postmenopausal women suffer at various periods of time from the symptoms of this estrogen deficiency, most notably vasomotor instability (hot flashes) and sleep disturbances. The tropic symptoms of estrogen deficiency have lasting and cumulative consequences, such as accelerated loss of 
bone density that eventually increases the risk of fractures; genitourinary atrophy resulting in dyspareunia and urinary atrophy; and lipoprotein changes with increased risk of coronary heart morbidity and mortality. ${ }^{1}$

Today, estrogen deficiency is mainly treated by oral estrogens (either conjugated equine urine-derived estrogens containing $<0.2 \% 17 \beta$-estradiol) in doses far in excess of what would be required by the parenteral route. Taken orally, estradiol is largely transformed to estrone through metabolism in the liver. Dosage for parenteral estrogen administration has been widely studied, including the different forms, eg, percutaneous creams, intranasal solutions, and vaginal gel. All of these administration forms result in a pronounced, transient elevation of plasma and saliva concentrations of $17 \beta$-estradiol, with little conversion to estrone and no first-pass hepatic effect, thus avoiding an increase in hepatic protein synthesis. Daily doses of $0.5 \mathrm{mg}$ or less achieving estradiol plasma levels between $65 \mathrm{pg} / \mathrm{mL}$ and $90 \mathrm{pg} / \mathrm{mL}$ are threshold values effective in reducing hot flashes. ${ }^{2}$ Endocrinological changes and dynamics during the menstrual cycle are described in detail elsewhere. ${ }^{2}$ This article refers to plasma concentrations.

Detailed analyses of the rhythms are difficult due to problems with sampling. The most convenient solution to this problem is the measurement of sex steroid concentrations in other biological fluids that are more easily available, such as urine or saliva. However, urinary values give only partial information of sex steroid metabolites. Sex steroids leak into saliva from plasma. However, only the free unbound fraction is involved. Albumin and sex hormone-binding globulin do not allow the bound fraction of the hormones to get into saliva, due to their molecular weights. Thus, salivary concentrations represent a valuable marker for the free, unbound, and biologically active fraction of the particular steroid. ${ }^{2}$

The dynamics of salivary steroids resemble the known dynamics in plasma. ${ }^{3}$ Saliva estradiol reaches the lowest levels during the early menstrual phase and the highest just around ovulation and at a secondary peak in the late luteal phase. ${ }^{3}$ Progesterone produced mainly by corpus luteum is found in the highest saliva concentrations during the luteal phase. $^{2}$ Salivary hormone levels and their pattern during cyclic 17ß-estradiol and progesterone percutaneous sex hormone replacement therapy have not been studied in such a manner yet.

The aim of our study was to use a combined estradiol and progesterone transdermal cream to i) estimate the saliva and serum levels of hormones after 3 and 6 months of administration of four various low doses of transdermal
$17 \beta$-estradiol and progesterone designed to mimic the secretory 28-day pattern seen in a normal, healthy cycling women; ii) determine whether such a protocol ameliorates climacteric symptoms; and iii) investigate the diurnal rhythm of $17 \beta$-estradiol by pharmacokinetic assessment of hormone uptake at various time points during a period of 24 hours after application of the cream.

\section{Methods}

The study in postmenopausal women was performed in Santa Barbara, California, USA, according to an open, nonrandomized, between-patient trial. The study protocol were reviewed and approved by the Internal Ethics Committee, Cottage Hospital, Santa Barbara. Each subject received oral and written information on the study and all signed a formal consent.

Twenty-nine healthy, nonhysterectomized women (age 44-56 years, mean 51 years) undergoing the physiological menopause ( $>$ 1year of amenorrhea) were enrolled in the trial and all completed the study. Ovariprival status was confirmed by plasma follicle-stimulating hormone (FSH) levels above $60 \mathrm{U} / \mathrm{L}$, saliva $17 \beta$-estradiol levels below $1.0 \mathrm{pg} / \mathrm{mL}$, and serum $17 \beta$-estradiol levels below $4 \mathrm{pg} / \mathrm{mL}$. None of the subjects had received sex steroids or other specific drugs for at least 8 weeks before evaluation.

All patients had typical symptoms of the climacteric syndrome and a Kupperman index (which takes into account the 11 most common symptoms corrected both by a weight factor and by a severity coefficient) of over $25 .{ }^{4}$ Patients were excluded if they had undiagnosed vaginal bleeding; severe metabolic, endocrine, or gastrointestinal disease; neoplasms; uncontrolled hypertension; or endometriosis or if they were smokers or were known to be alcohol or drug abusers.

The hormones under investigation were micronized $17 \beta$-estradiol combined with micronized progesterone in a lipophilic base cream developed for transdermal administration. The cream was packed in units of seven wells, each containing $1 \mathrm{~mL}$ of cream. Hormones from a total of four units containing four different doses of combined $17 \beta$-estradiol plus progesterone were administered during a period of 4 weeks. A new 4-week cycle was then started. Hormone doses applied were as follows: $0.05 \mathrm{mg} / \mathrm{mL}$ $17 \beta$-estradiol plus $25 \mathrm{mg} / \mathrm{mL}$ progesterone administered daily during week $1,0.30 \mathrm{mg} / \mathrm{mL} 17 \beta$-estradiol plus $50 \mathrm{mg} / \mathrm{mL}$ progesterone administered daily during week $2,0.20 \mathrm{mg} / \mathrm{mL}$ $17 \beta$-estradiol plus $100 \mathrm{mg} / \mathrm{mL}$ progesterone administered daily during week 3 , and $0.10 \mathrm{mg} / \mathrm{mL} 17 \beta$-estradiol plus $100 \mathrm{mg} / \mathrm{mL}$ progesterone administered daily during week 4 . 
The subjects applied $1 \mathrm{~mL}$ of the cream on a specific small area of $\sim 200 \mathrm{~cm}^{2}$ of the anterior thigh. On study days, as well as days with saliva sampling, the cream was applied at 08.00.

For determination of $17 \beta$-estradiol and progesterone at baseline, saliva and blood samples were taken on day 1 before the first application of the cream. Samples were taken on day 6 of week 2 at $T=6$ hours after 3 and 6 months of treatment. Serum FSH and $17 \beta$-estradiol were assayed by extraction chromatography and radioimmunoassay. For pharmacokinetic data, saliva samples were taken on day 6 of week 2 immediately before application and then subsequently after 6,12 , and 24 hours. Saliva $17 \beta$-estradiol and progesterone concentrations were analyzed using high-performance liquid chromatography (HPLC) analysis (PerkinElmer ${ }^{\circledR}$ Series 200 HPLC system; PerkinElmer Life and Analytical Sciences, Shelton, CT, USA).

For statistics, all data were analyzed by a means model repeated-measures analysis of absolute changes from baseline with SAS Proc Mixed ${ }^{\circledR}$ (Version 8.02, SAS Institute Inc., Cary, NC, USA) and shown as the arithmetic mean \pm standard deviation.

\section{Results}

As shown in Table 1, plasma levels of FSH presented a significant fall at each time point versus baseline. There was a similar significant fall in the Kupperman index after 3 and 6 months of treatment versus baseline.

After 3 and 6 months of treatment, saliva $17 \beta$-estradiol and progesterone levels significantly increased, as shown in Table 2. Mean observed $17 \beta$-estradiol saliva concentrations obtained with week 2 protocol designed to mimic week 2 of the menstrual cycle $(0.30 \mathrm{mg} / \mathrm{mL} 17 \beta$-estradiol plus $50 \mathrm{mg} / \mathrm{mL}$ progesterone) on day 6,6 hours after morning application, significantly increased after 3 and 6 months of treatment. Each time point versus baseline was significantly increased to saliva values close to those of the early follicular phase ${ }^{3}(0.6 \pm 0.3$ vs $10.4 \pm 2.6$ vs $14.1 \pm 3.3 \mathrm{pg} / \mathrm{mL} ; P<0.01)$. The ratio between baseline value and 6-month treatment value was 23.5. Mean observed

Table I Serum follicle-stimulating hormone $(\mathrm{FSH})$ in $\mathrm{mIU} / \mathrm{mL}$ and Kupperman index before and during transdermal $17 \beta$-estradiol and progesterone (mean \pm standard deviation)

\begin{tabular}{lll}
\hline & $\begin{array}{l}\text { FSH } \mathbf{~ m I U} / \mathbf{m L} \\
(\mathbf{n}=16)\end{array}$ & $\begin{array}{l}\text { Kupperman index } \\
(\mathbf{n}=\mathbf{2 9})\end{array}$ \\
\hline Basal & $128 \pm 28.2$ & $30.3 \pm 5.4$ \\
3 months & $90.8 \pm 11.9 *$ & $11.1 \pm 3.2^{* *}$ \\
6 months & $44.4 \pm 13.0^{* *}$ & $5.2 \pm 2.2^{* *}$ \\
\hline
\end{tabular}

Notes: $* P<0.05$ vs baseline; $* * P<0.01$ vs baseline. saliva progesterone levels were significantly increased. Also, serum $17 \beta$-estradiol concentrations increased significantly $(3.3 \pm 2.8$ vs $47.9 \pm 14.7$ vs $80.6 \pm 19.9 \mathrm{pg} / \mathrm{mL} ; P<0.01)$. The ratio of baseline value and 6-month treatment value was 24.2 , which is of same magnitude as the saliva data (23.5), indicating a correlation between saliva and serum $17 \beta$-estradiol levels.

Saliva samples for pharmacokinetic assessment were collected at various time points on day 6 of week 2: $T=0$ (just before morning application ), $T=6, T=12$, and $T=24$ hours after application of the cream. Mean saliva concentration-time profiles of $17 \beta$-estradiol and progesterone are shown in Table 3. Highest saliva levels of both hormones were observed 6 hours after application. Saliva levels decreased to levels close to baseline values 24 hours after application. A similar diurnal rhythm is observed in normally cyclic women during reproductive life.

\section{Discussion}

This open, between-patient study validated a novel concept of biorhythmic estrogen therapy achieved by transdermal administration of $17 \beta$-estradiol during periods of 4 weeks, where four different doses of $0.05 \mathrm{mg}, 0.30 \mathrm{mg}, 0.20 \mathrm{mg}$, or $0.10 \mathrm{mg}$, respectively, were applied daily during 4 consecutive weeks to highly symptomatic women. Also, biorhythmic doses of progesterone were administrated daily in doses of $25 \mathrm{mg}, 50 \mathrm{mg}, 100 \mathrm{mg}$, or $100 \mathrm{mg}$ progesterone, respectively, each of the consecutive weeks. The study ended after 6 months of treatment without adverse effects. The study demonstrated that transdermal $17 \beta$-estradiol plus progesterone significantly reduced the number of objectively measured hot flashes and relieved typical climacteric symptoms, as evaluated by multiple clinical criteria (Kupperman index). The positive effect was present after 3 months, and subsequently was enhanced after 6 months. The physiological importance of our study is highlighted by saliva concentrations obtained by week 2 that closely mimic the estradiol maximal level typifying the early follicular phase of the normal menstrual cycle. ${ }^{3}$ Simultaneously, serum levels of $17 \beta$-estradiol were estimated before and after 3 and 6 months of treatment. The concentration increased from $3.3 \mathrm{pg} / \mathrm{mL}$ to $80.6 \mathrm{pg} / \mathrm{mL}$, which is a value sufficient to relieve climacteric symptoms. ${ }^{1,2}$

The pharmacokinetic experiments showed that highest saliva concentrations of $17 \beta$-estradiol and progesterone were obtained 6 hours after morning application of the cream. Twenty-four hours after application, saliva concentrations of both steroids reached baseline values. This is the first 
Table 2 Saliva 17 $\beta$-estradiol and progesterone and serum I7 $\beta$-estradiol. Samples were collected 6 hours after morning application on day 6 of the week 2 protocol $(0.3 \mathrm{mg}$ estradiol plus $100 \mathrm{mg}$ progesterone). Basal values represent concentrations before treatments (mean \pm standard deviation)

\begin{tabular}{lccc}
\hline & $\begin{array}{l}\text { Saliva } 17 \beta \text {-estradiol } \mathbf{~ p g} / \mathrm{mL} \\
(\mathbf{n}=16)\end{array}$ & $\begin{array}{l}\text { Serum } 17 \beta \text {-estradiol } \mathbf{~ g g} / \mathrm{mL} \\
(\mathbf{n}=\mathbf{6})\end{array}$ & $\begin{array}{l}\text { Saliva Progesterone } \mathbf{p g} / \mathrm{mL} \\
(\mathbf{n}=16)\end{array}$ \\
\hline Basal & $0.6 \pm 0.3$ & $3.3 \pm 2.8$ & $135 \pm 51$ \\
3 months & $10.4 \pm 2.6^{*}$ & $47.9 \pm 16.7^{*}$ & $2414 \pm 144^{*}$ \\
6 months & $14.1 \pm 3.3^{*}$ & $80.6 \pm 21.9^{*}$ & $2840 \pm 276^{*}$ \\
\hline
\end{tabular}

Note: $* P<0.01$ vs baseline.

time a biorhythmic protocol has been applied for treatment of climacteric symptoms, which prompts the question of whether $17 \beta$-estradiol in biorhythmic cyclic doses administered to postmenopausal women contributes to realignment of biological time linked to reproductive cycles. In mammals, most body functions follow a rhythmic pattern adjusted to a 24-hour period. Circadian rhythmicity is an evolutionarily conserved property that regulates numerous functions in the human body, including sleep and wakefulness, body temperature, blood pressure, hormone production, digestive secretion, and immune activity. ${ }^{5}$ A central rhythm generator is located in the suprachiasmatic nucleus $(\mathrm{SCN})$ of the hypothalamus and consists of multiple, autonomous singlecell circadian oscillators, which are synchronized to fire rhythmically, generating a coordinated, rhythmic output in intact animals. ${ }^{6}$

Interestingly, it has been demonstrated that as many as one-third of the neurons afferent to the SCN are estrogen receptor $\alpha$-immunoreactive. ${ }^{7}$ The cellular mechanism of circadian rhythmicity involves the regulation of three Period genes (Per 1-3) and two cytochrome genes (Cry 1 and Cry). ${ }^{6}$ Per-2 has been reported to function as a tumor suppressor gene. ${ }^{8}$ Per-2 is expressed in normal mammary epithelium and at a reduced level in breast cancer cells, leading to an alteration in the cell cycle, cell growth, and cell survival. The biological clocks are synchronized by central

Table 3 Dynamic changes of saliva I $7 \beta$-estradiol and progesterone after 6 months of treatment. Saliva samples were collected during day 6 after application of week 2 protocol $(0.3 \mathrm{mg}$ 17 $\beta$ estradiol plus $100 \mathrm{mg}$ progesterone) at various time points (h) (mean \pm standard deviation)

\begin{tabular}{lcc}
\hline & $\begin{array}{l}\text { I7 } \beta \text {-estradiol } \mathbf{~ p g} / \mathbf{m L} \\
(\mathbf{n}=\mathbf{6})\end{array}$ & $\begin{array}{l}\text { Progesterone } \mathbf{~ g g} / \mathbf{m L} \\
(\mathbf{n}=6)\end{array}$ \\
\hline$T=0$ & $4.1 \pm 2.0$ & $682 \pm 119$ \\
$T=6$ & $18.8 \pm 4.0^{*}$ & $1812 \pm 211^{*}$ \\
$T=12$ & $12.2 \pm 4.2^{*}$ & $1613 \pm 445^{*}$ \\
$T=24$ & $5.3 \pm 2.4$ & $856 \pm 114$ \\
\hline
\end{tabular}

Note: $* P<0.01$ vs baseline. pacemaker through complex interaction of neural, humoral, and behavioral cues. ${ }^{9}$ A variety of factors have been unraveled with the potential to reset circadian rhythms in SCN and peripheral cells, such as estradiol and progesterone, ${ }^{10,11}$ by inducing an acute activation of Per- 1 and Per- 2 expression.

It is therefore of considerable interest to consider the possibility that endogenous fluctuations in estradiol and progesterone levels may modulate clock gene expression in $\mathrm{SCN}$, as well as in a number of peripheral tissues. Moreover, given the proposed association between clock gene expression, the cell cycle, and tumor growth, this is one route through which estradiol and progesterone in cycling low doses that mimic a normal menstrual cycle might downregulate susceptibility to cancer development. ${ }^{12-14}$

The menstrual cycle is an endocrine clock orchestrated by circulating levels of ovarian steroids, ie, estrogen and progesterone. The biological actions of estrogens are mediated mainly by estrogen receptors (ER $\alpha$ and ER $\beta$ ), which bind to estrogen response elements in the regulatory regions of target genes and associate with basal transcription factors and tissue-specific cofactors to alter gene expression. ${ }^{15}$ Because the transcriptional regulation is a key feature of both the circadian machinery and the ER pathway and the proposed connection between the clock genes and breast cancer, Gery and Koeffler ${ }^{13}$ suggested that the ER signaling is yet another front on which core clock factors may exert their effects. It was found ${ }^{13}$ that Per2 is a novel estrogeninducible ER cofactor. Per2 binds to ER $\alpha$, enhances receptor degradation, and suppresses estrogen-mediated transcription of ER target genes in breast cancer cells. In turn, Per2 itself is estrogen inducible in these cells, hence suggesting a feedback mechanism to attenuate estrogen response that couples the circadian clock to the estrogen pathway. Linking Per2 to the estrogen pathway indicates a strong tumor suppressor function in breast tissue that leads to proliferation arrest, growth inhibition, and apoptosis associated with downregulated expression of Cyclin D1, c-Myc, and p21. ${ }^{13}$ 
The finding that circadian oscillators in select regions of the limbic forebrain are modulated by endogenous changes in estrogen adds a previously unrecognized level of complexity to the organization of the circadian system. ${ }^{16}$ Hence, considering the strong relationships between sleep difficulties and depressive symptoms, the control of circadian rhythms by estrogen-regulated molecular mechanisms described previously may represent a novel biomedical area that indirectly affects the mood and wellbeing of menopausal women. The significance of these findings is also in favor of an implication of estrogen in the modulation of neuronal activity in SCN and thus possibly its ability to re-establish circadian rhythms in menopausal women.

All the women before the study had severe climacteric symptoms, as indicated by a Kupperman index of 30 . After 6 months of hormone treatment, these symptoms were significantly attenuated and the Kupperman index decreased to a value of 7 . In particular, the ability to fall asleep, decreased restlessness, and reduced depressive symptoms were observed, which suggests that a synchronization (Zeitgeber mechanism) between circadian clock rhythms and the rhythms of estradiol rise and fall during treatment might have taken place in the control center for the menopausal women's sleep cycles.

Based on these results, we propose that investigators must translate both basic science and clinical outcomes to decide the safest, most efficacious treatment for patients with climacteric symptoms. Evidence-based medicine involves the synthesis of all available data when comparing therapeutic options for patients. But evidence-based medicine does not mean that data from pilot studies should be ignored until a randomized controlled trial of particular size and duration is completed. Rather, it demands an assessment of the current available data to decide which therapies are likely to carry the greatest benefits and lowest risk for patients. Based on both physiological results and clinical outcome, our study demonstrates that bioidentical hormones are associated with better clinical results than their nonbiological counterparts. Until there is evidence to the contrary, bioidentical hormones transdermally ${ }^{17,18}$ administered in biorhythmic cyclic doses are the preferred modality of HRT. But larger studies are needed to determine the long-term (5-10 years) effects of the therapy.

\section{Disclosure}

The authors report no conflicts of interest in this work.

\section{References}

1. Palacios S. Advances in hormone replacement therapy: making menopause manageable. BMC Women's Health. 2008;8:22-25.

2. Holtorf K. The bioidentical hormone debate. Postgrad Med. 2009; 121(1):4-9.

3. Celec P, Ostatníková D, Skokňová M, et al. Salivary sex hormones during menstrual cycle. Endocr J. 2009;56:521-523.

4. Kupperman HS, Wetchler BB. Contemporary therapy of the menopausal syndrome. JAMA. 1959;171:1627-1637.

5. Albrecht U, Eichele G. The mammalian circadian clock. Curr Opin Genet Dev. 2003;13:271-277.

6. Reppert M, Weaver DR. Molecular analysis of mammalian circadian rhythms. Ann Rev Physiol. 2001;63:647-676.

7. Kruijver EP, Swaab DF. Sex hormone receptors are present in the human supra-chiasmatic nucleus. Neuroendocrinology. 2002;75:296-305.

8. Fu L, Pelicano H, Liu J, et al. The circadian gene Period2 plays an important role in tumor suppression and DNA damage response in vivo. Cell. 2002;111:41-50.

9. Schibler U, Sasssone-Corsi P. A web of circadian pacemakers. Cell. 2002;111:919-922.

10. He P-J, Hirata M, Yamauchi N, et al. Up-regulation of Per1 expression by estradiol and progesterone in the rat uterus. J Endocrinol. 2007;194: 511-519.

11. Xiang S, Coffelt SB, Mao L, et al. Period-2: a tumor suppressor gene in breast cancer. J Cir Rhythms. 2008;6:4-10.

12. Gery S, Virk RK, Chumakov K, et al. The clock gene Per2 links the circadion system to the estrogen receptor. Oncogene. 2007;26: 7916-7920.

13. Gery S, Koeffler H. The role of circadian regulation in cancer. Cold Habor Symp Quantiv Biol. 2007;72:459-464.

14. Chen S-T, Choo K-B, Hou M-F, et al. Deregulated expression of the PER1, PER2 and PER3 genes in breast cancer. Carcinogenesis. 2005;26:1241-1246.

15. McDonnell D, Norris J. Connections and regulation of the human estrogen receptor. Science. 2002;296:1642.

16. Fatehi M, Fatehi-Hassanabad Z. Effects of 17 beta-estradiol on neuronal cell excitability and neurotransmission in the suprechiasmatic nucleus of rat. Neuropsychopharmacology. 2008;33:1354-1364.

17. Buster JE. Transdermal menopausal hormone therapy: delivery through the skin changes the rules. Expert Opin Pharmacother. 2010;11:1489-1499.

18. Mahmud K. Natural hormone therapy for menopause. Gynecol Endocrinol. 2010;26:81-85.

International Journal of General Medicine

\section{Publish your work in this journal}

The International Journal of General Medicine is an international, peer-reviewed open-access journal that focuses on general and internal medicine, pathogenesis, epidemiology, diagnosis, monitoring and treatment protocols. The journal is characterized by the rapid reporting of reviews, original research and clinical studies across all disease areas.

\section{Dovepress}

A key focus is the elucidation of disease processes and management protocols resulting in improved outcomes for the patient.The manuscript management system is completely online and includes a very quick and fair peer-review system. Visit http://www.dovepress.com/ testimonials.php to read real quotes from published authors. 